\title{
Analysis on the Current Situation of the Self-Innovation of China's Manufacturing Industry Based on Structural Equation
}

\author{
Min Zhang ${ }^{1} \&$ Chuan Lian Song ${ }^{1,2}$ \\ ${ }^{1}$ School of Economics and Science, Chang Chun University of Science and Technology, Chang Chun, China \\ ${ }^{2}$ School of Photoelectric information, Chang Chun University of Science and Technology, Chang Chun, China \\ Correspondence: Min Zhang, School of Economics and Science, Chang Chun University of Science and \\ Technology, The first building 403room, Satellite road 7989, Chang Chun, China. E-mail: zmzs10118@163.com
}

Received: April 22, 2013

doi:10.5539/ijbm.v8n15p124

\author{
Accepted: May 16, 2013 \\ Online Published: July 12, 2013 \\ URL: http://dx.doi.org/10.5539/ijbm.v8n15p124
}

\begin{abstract}
Manufacturing industry is the material foundation of national economy, the foundation of social progress and a rich country. It plays decisive role especially for China, which is a large manufacturing power. Self-innovation is one of the strategies of sustainable development of Chinese economy; it is also the correct channel to improve the competitiveness. Therefore, the self-innovation of manufacturing industry directly affects the competitiveness of our country. This article utilizes the basic principle of structural equation to establish the path diagram of influencing factor of self-innovation of manufacturing industry. Through path analysis, the author calculated the path coefficient of self-innovation of manufacturing industry, measured the situation of self-innovation of manufacturing industry in the current stage, and made effective analysis on it, provided solution and suggestion for the development of China's manufacturing industry.
\end{abstract}

Keywords: manufacturing industry, self-innovation, structural equation

\section{Introducation}

With the gradual deepening of process of global economic integration and the continuous improvement of investment environment and infrastructure in China, large potential for economic development, cheap labor force resources and market with great potential has attracted the attention of multinational companies in the world. To transfer the manufacturing base to China has become an important development strategy for many multinational companies, which provided good development opportunity for the development of China's manufacturing industry. From small commodities to the large scale machine, "made in China" existed at each corner. China is producing more and more commodities for the world. Over the past two decades, Chinese manufacturing industries have played a key role in the rapid growth of the Chinese economy. At present, the total amount of China's manufacturing ranked fourth in the world; the output of 172 types of products ranked first in the world. China's industrial output and nearly two thirds of the economy's total industrial assets.Therefore, China has become the real "manufacturing power". However, because of lacking technology innovation mechanism and protection measures, China's manufacturing industry didn't have the proprietary intellectual property rights and brand connotation, which was still under the stage of simple imitation and repeated production of low added-value product. Many local Chinese enterprises were still the foundry for other enterprises. The products of their own were very few, which was inappropriate to the current situation that emphasized intellectual property right. As long as the ending of the seventh CCP meeting, the keynote report by $\mathrm{Hu}$ Jintao emphasized the strong desire on self-innovation in China: "until 2020, step into the list of innovate-style country", which provided higher requirement for future development of manufacturing industry - one of the pillar industry in China.

The model of structural equation is one of the important new-rising research method and statistic technologies of modern society and behavior science research quantization model. It integrated two statistic technologies: factor analysis and regression analysis; it also affected the application of the principle of research and design and the method of measurement. This article will utilize the model of structural equation and make path analysis on the factors of self-innovation of China's manufacturing industry, and accordingly evaluate the situation of self-innovation of manufacturing industry. Based on that the article made effective analysis and provided solution and suggestion of future development of China's manufacturing industry. 


\section{Establishment of Model of Structural Equation}

\subsection{Basic Principle of Structural Equation}

The model of structural equation SEM is the model for Empirical Analysis; it is a series of equations that reflected the invisible variable and visible variable; the purpose is that through the measurement of visible variable to deduce invisible variables and make a test on the correctness of the Presumptive models. Compared with the traditional calculation method, it had many advantages, including variance analysis, regression analysis path analysis and factor analysis, and the covariance matrices based on the variables to analyze the relationship among variables, handled with the relationship between multiple reasons and results. SEM consists of two components, a measurement model and a structural model. For this project, the measurement model includes the relationships between the dimensions (environmental performance model sub-categories) and the questionnaire items (indicators).

The model of structural equation was widely used in the field of social science; the research characteristic was that many research variables can not be directly observed and measured (Hoyle, 1995). The basic principle was described as follows:

1). Measurement model, also called Confirmatory Factor Analysis, it mainly expressed the relationship between Observed Variable and invisible variable. It was usually composed by two equations, the form of model was:

$$
\begin{aligned}
& x=\Lambda x \xi+\delta \\
& y=\Lambda y \eta+\varepsilon
\end{aligned}
$$

Among them, $\mathrm{x}$ was the exterior observed variable, $\xi$ was the exterior invisible variable; $\Lambda \mathrm{x}$ was the coefficient matrix that reflected the relationship of $\mathrm{x}$ on $\xi$, $\delta$ was the error of measurement of $\mathrm{x}$; $\mathrm{y}$ was the interior observed variable, $\eta$ was the interior invisible variable, $\Lambda$ y was the coefficient matrix that reflected the relationship of $y$ on $\eta, \varepsilon$ was the error of measurement of $y$.

2). Structural model, also called Causality of Invisible Variable Model, it mainly expressed the relationship between invisible variable, the form of model was:

$$
\eta=B \eta+\Gamma \xi+\zeta
$$

The interior invisible variable and exterior visible variable were connected by $\mathrm{B}$ and $\Gamma$ coefficient matrix and Error vector $\xi$; $\Gamma$ and B respectively represented the matrix composed by the path coefficient between the interior invisible variable and exterior visible variable; $\zeta$ was the error term. Through the establishment of the model we can obtain the basic parameter matrix, load factor matrices, coefficient matrix of $B$ and $\Gamma$ structure path, covariance matrices of exterior invisible variable $\xi$ and covariance matrices of observed error term $\delta$ and $\varepsilon$ Model setting was to set a whole series of model parameter contained in the above matrix. The calculation process was complicated; we can resort to the professional software. We usually depend on the path route to paint the initial model. Through software analysis, we can determine the rationalism of the model and make amendment (Huang Fangming, 2005). Although SEM is a family of techniques, they all share the same basic analytical sequences.

Although SEM is a family of techniques, they all share the same basic analytical sequences. The steps are briefly described as follows (Hussey, 2007):

a. Specify a theoretically-based model. The researcher expresses his/her hypothesis in the form of a structure model, which can take the form of a picture or series of equations.

b. Construct a path diagram of causal relations. The investigator defines the exogenous and endogenous constructs and links relationships in a path diagram.

c. Convert the path diagram into a set of structural and measurement models. At this stage the researcher specifies the model in more formal terms. This is done through a series of equations that define structural equations linking constructs; the measurement model specifying which variables measure which constructs; and a set of matrices indicating hypothesized correlations among the constructs or variables.

d. Choose the input matrix type and estimate the proposed model. At this stage the investigator has to confirm that the assumptions of SEM address missing data issues and determine if the model will use covariance matrices or correlation matrices for data input.

e. Assess the structural model. A model is identified to determine if there are sufficient equations to "solve" each of the coefficients (unknowns) to be estimated. The researcher desires to have an over-identified (more equations than estimated coefficients and degrees of freedom greater than zero) model. 
f. Evaluate the model fit. Use goodness-of-fit measures to determine how adequately the model accounts for the data.

g. Interpret the results and, if necessary, modify the model.

Structural equation modeling is appropriate for data in which a series of regressions are being performed; the dependent variable for one regression analysis is also the independent variable for another. Structural equation modeling can be used by universities, government agencies and larger companies to validate environmental performance models.

\subsection{SEM's Three Central Principles}

More specifically, SEM is an approach to research guided by three central principles that are of philosophical and practical value to any model builder.

First, many if not most scientific constructs have many facets and cannot be directly observed. They can only be measured through observable measures or indicators that vary in their degree of observational meaningfulness and validity. No single indicator can capture the full theoretical meaning of the underlying construct and hence, multiple indicators are necessary. SEM's uncompromising focus on construct operationalization is probably its most distinguishing feature and contribution to marketing science.

Second, observed measures of theoretical constructs are invariably contaminated by measurement error, and the correspondence between constructs and their measures has to be an explicit component of marketing models. The interplay between constructs and measures plays a crucial role in theory development and model testing, and in deriving empirical generalizations.

Third, models are always simplified representations of reality and before any conclusions are derived from a model, the degree to which the model is in agreement with the data has to be ascertained. Compared to other modeling techniques, SEM is more focused on explaining marketing phenomena than on predicting specific outcome variables.

\subsection{The Establishment of Index System}

The purpose of this article was to analyze the situation of self-innovation in China's manufacturing industry. Consequently, a number of studies suggested that a multi-factor performance measurement model should be used to characterize it (Bagozzi,1982). According to the rule and characteristic of self-innovation in manufacturing industry, based on the principle of scientificity、 normative、 popularity and operability, this article chose three invisible variables of self-innovation in manufacturing industry (reflected by seven visible variables) namely the input of self-innovation of manufacturing industry (reflected by the input of R\&D staff and the expense ); the implementation of project of self-innovation of manufacturing industry (reflected by the number of enterprises that carried out self-innovation and the number of R\&D project); technology acquisition of manufacturing industry (reflected by expense of foreign technology introduction, expense of digestion and absorption, expense of buying domestic technology). In addition, according to the requirement of the method, another two visible variables for effectively measuring self-innovation of manufacturing industry were selected, namely the revenue of new product sales and the number of possessing patent for invention (Chin, 2003).To sum up, establish the index system as Table 1. 
Table 1. Index of self-innovation in manufacturing industry

\begin{tabular}{|c|c|c|c|c|c|c|c|}
\hline $\begin{array}{l}\text { Variable } \\
\text { name }\end{array}$ & Visible variable & Variable name & $\begin{array}{l}\text { Invisible } \\
\text { variable }\end{array}$ & $\begin{array}{l}\text { Variable } \\
\text { name }\end{array}$ & $\begin{array}{l}\text { Invisible } \\
\text { variable }\end{array}$ & $\begin{array}{c}\text { Variable } \\
\text { name }\end{array}$ & $\begin{array}{l}\text { Invisible } \\
\text { variable }\end{array}$ \\
\hline V1 & $\begin{array}{l}\text { Number of } \mathrm{R} \& \mathrm{D} \\
\text { input }\end{array}$ & \multirow[t]{2}{*}{ Investment } & \multirow{2}{*}{$\begin{array}{c}\text { Situation of } \\
\text { self-innovation } \\
\text { input }\end{array}$} & \multirow[t]{8}{*}{ Innovation } & \multirow[t]{8}{*}{ Self-innovation } & \multirow[t]{3}{*}{ V8 } & \multirow{3}{*}{$\begin{array}{c}\text { Revenue of } \\
\text { new } \\
\text { product } \\
\text { sales }\end{array}$} \\
\hline V2 & $\begin{array}{l}\text { Amount of } R \& D \\
\text { input }\end{array}$ & & & & & & \\
\hline V3 & $\begin{array}{l}\text { Number of } \\
\text { enterprise carried } \\
\text { out self-innovation }\end{array}$ & \multirow[t]{2}{*}{ implement } & \multirow[t]{2}{*}{$\begin{array}{c}\text { Situation of } \\
\text { self-innovation } \\
\text { implementation }\end{array}$} & & & & \\
\hline V4 & $\begin{array}{l}\text { Number of } R \& D \\
\text { project }\end{array}$ & & & & & \multirow[t]{5}{*}{ V9 } & \multirow{5}{*}{$\begin{array}{c}\text { Amount of } \\
\text { patent } \\
\text { possession }\end{array}$} \\
\hline V5 & $\begin{array}{l}\text { Expense of foreign } \\
\text { technology } \\
\text { introduction }\end{array}$ & Technology & $\begin{array}{l}\text { Technology } \\
\text { acquisition } \\
\text { situation }\end{array}$ & & & & \\
\hline V6 & Expense of digestion & & & & & & \\
\hline V7 & Expense of buying & & & & & & \\
\hline & Domestic technology & & & & & & \\
\hline
\end{tabular}

Discription: The data was from the China Statistical Yearbook in 2006 and the statistic material of self-innovation of large and medium size industrial enterprises in 2011. The object for analysis was the large and medium size enterprises in manufacturing industry. The analysis software was adopted the Amos7.0 in SPSS17.0.

\subsection{Result of Model Establishment and Calculation of Path Analysis}

According to the index system of Tab.1, establish the route path of influencing factors of self-innovation ability, among them, the ellipse represented the invisible variable; matrix represented the visible variable; Ei represented random error; the variance was set as the fixed value 1, utilize the maximum likelihood method of path analysis for analysis.

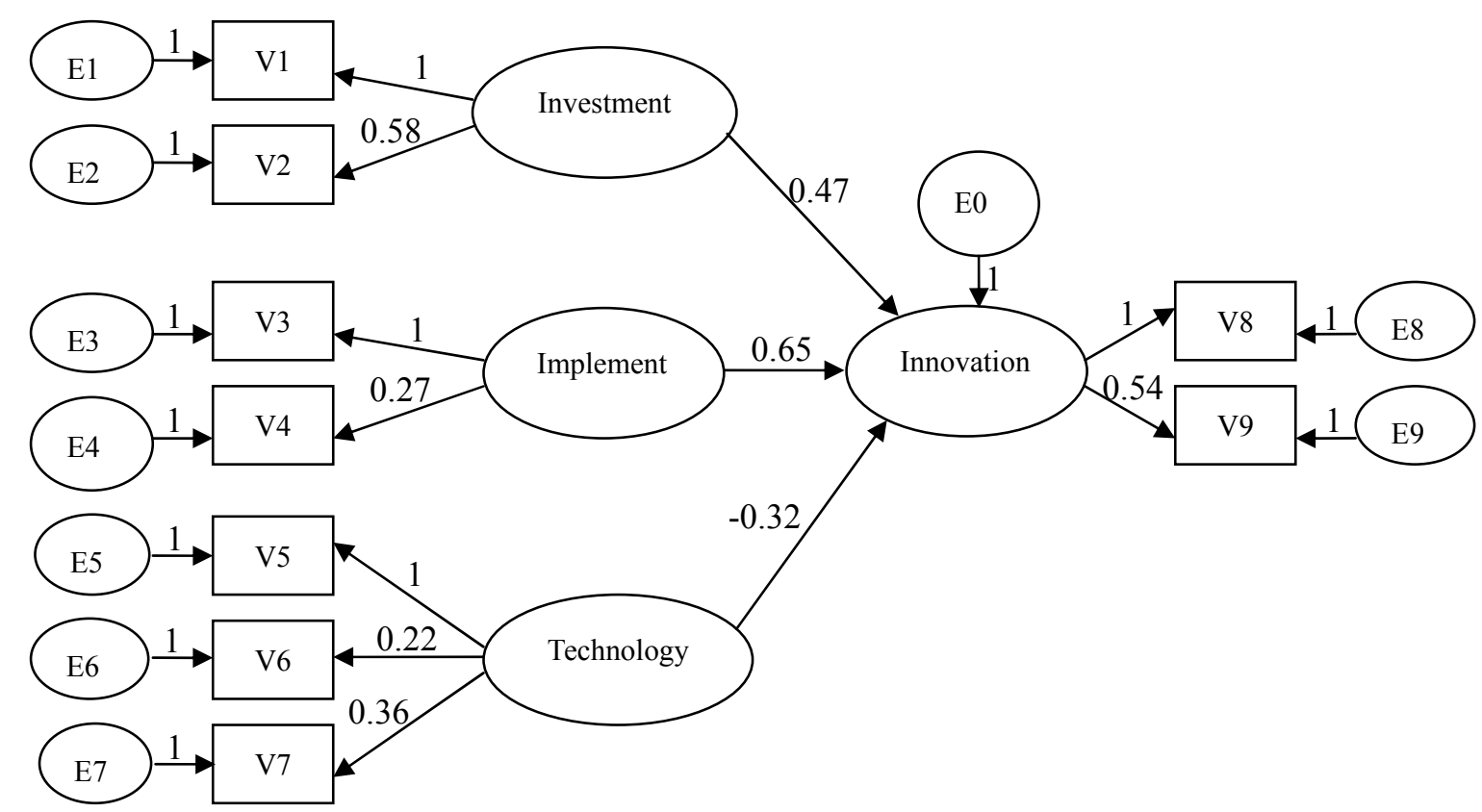

Figure 1 . The route path of influencing factors of self-innovation ability of manufacturing industry

Through path analysis, the evaluated value of three invisible variables on the influencing coefficient of self-innovation were obtained, among them the effect of technology acquisition $(-0.32)$ was negative, input of self-innovation (0.47) and the implementation of self-innovation project $(0.65)$ had positive effect on the self-innovation of manufacturing industry. 


\section{Result Analysis of Structural Equation and Solution}

According to the result of structural equation, we gave an analysis on the items of the model.

(1) The input of self-innovation (0.47). The effect of this project on the self-innovation of manufacturing industry was not very strong; on one hand, the cycle of input of implementation of self-innovation was quite long; obvious effect cannot be seen in a short time; the input and output was not necessarily in proportion. On the other hand, the input of R\&D expense and human resource in China's manufacturing was insufficient; which didn't play sufficient role in promoting the self-innovation. The material in 2004 showed that the expense of R\&D of America accounted for $2.68 \%$ of GDP; in Japan the number was 3.13\%; in Korean the number was $2.85 \%$, while in China the number was $1.23 \%$. This index was reflected by two visible variables: the ratio of R\&D staff among the staff of the whole industry, the degree of input of R\&D expense. The ratio was 1:0.58, which showed that the factor of human played a great role in measuring the input.

Recently, self-innovation of manufacturing in China is gradually attached great importance, the input of expense and human resource increases continuously; especially the high-tech industry (medicine, chemistry, electronic, communication and so on). In 2000, the input of R\&D staff of high-tech industry was 92000; the input of expense of R\&D was 1.116 RMB; in 2006, the input of R\&D staff of high-tech industry was 189,000; the input of expense of R\&D was 4.564 RMB with fast speed of growth. The potential of China's manufacturing is large with huge market. Continue to increase the input of R\&D, especially the input of high-tech industry with the combination of manufacturing and high technology to create our own high technology product is the key to the development of manufacturing.

(2) The implementation of self-innovation (0.65). From the perspective of path coefficient, the implementation of self-innovation of manufacturing was quite good, which played an positive role. In recent years, our China always showed the concern to the self-innovation activity. The original data material showed that there was 6476 enterprises of manufacturing carried out self-innovation in 2005, which accounted for $25.5 \%$. The number of R\&D was 30669. In terms of future development, manufacturing industry should combine the development of R\&D project and enterprise development closely; promote the transformation of scientific and technological achievements. The comprehensive implementation of innovation is the powerful guarantee for manufacturing industry to improve self-innovation ability.

During the economic reform process, China's government employed bridging institutes to transfer the relevant functions of the innovation system formerly implemented by public research institutes to the principal performers of innovation, namely enterprises. China's bridging institutes serve as intermediaries among actors in the innovation system, as well as providing the innovation-related infrastructure for these actors.

(3) The acquisition of the technology of self-innovation (-0.32). The situation of Technology acquisition played negative effect on self-innovation, which showed that technology introduction didn't play positive role on self-innovation. Technology introduction should promote the development of self-innovation. But now the innovation of manufacturing industry was focused on imitation, which was under the transition stage from simple imitation to self-innovation. China's economy is still going through the catch-up stage, and thus generally needs to import technology and may benefit from late development (Amsden, 1989). Through the way of technology introduction, enterprises absorb mature, advanced technological achievement home and abroad, and then imitate and innovate under this basis. It is the shortcut to shorten the gap with the developed countries. Japan and Korea changed the backward appearance and became the economic power through imitation and innovation. Like China, Korea also aggressively imported technology, although primarily and with extensive support from the United States. Unlike China, however, the Korean manufacturing firms invested in developing their own R\&D capabilities first to imitate and then to improve on world-class technology.If we can correctly carry out this strategy and cultivate our talent team during imitation and innovation, strengthen our research and development power, finally we can step to the self-innovation stage. At the same time, too much relying on the technology introduction should be avoided.

Technology acquisition includes the ratio of foreign technology expense among the R\&D expense of each industry, the ratio of absorption expense among the R\&D expense of each industry, the ratio of buying domestic technology expense of the R\&D expense of each industry. The ratio of path coefficient was 1:0.22:0.36. It was showed that the technology acquisition of manufacturing industry at current stage was to buy the foreign technology. In addition, the ratio of digestion and absorption expense was very low. We should increase more expense, put the focus on the aspects of digestion and absorption and absorb the advanced achievement for our own use and finally achieve the ability of self-innovation avoiding the pursuit of short term interest.

(4) Two visible variables for measuring self-innovation. It included two aspects: revenue of new product sales 
and the number of patent holding. The ratio of path coefficient was 1:0.54. We can see that in terms of the output of self-innovation of manufacturing, they pursued the new product to guarantee the improvement of profitability in a short period while ignoring the acquisition of intangible asset patent. The weak consciousness of Chinese enterprises on the creation and protection of the patent technology was a common phenomenon. With the gradual deepening of internationalism, the effect of intellectual property right was prominent. The lack of patent means that each step for enterprises to move forward will cost a lot, which is unfavorable to the prosperity of development of manufacturing industry.

Manufacturing industry should establish the consciousness of brand, pay attention to the acquisition of intellectual property and key technology and strengthen the scientific innovation. Scientific innovation is the strong motive to promote the growth of China's manufacturing. Only through scientific innovation, gradually master the technology which is decisive to the development of industry and material production ability can we get rid of the current situation of relying on the foreign country too much. To possess our own intellectual property and key technology is the goal for Chinese enterprises. What we pursue is not only made in China but also created in China. Only in this way, can we realize the fundamental transformation of large manufacturing country to strong manufacturing country.

\section{Acknowlegement}

This work was financially supported by Social Science Foundation of Jilin Province of China (2013BS55). We thank the sustentation fund for this article.

\section{References}

Amsden, A. H. (1989). Asia's Next Giant: South Korea and Late Industrialization. Oxford University Press, New York, NY: Viking Press.

Bagozzi, R. P., Phillips, L. W. (1982). Representing and testing organizational theories: A holistic construal. Administrative Science Quarterly. Harvard Business Review, 76(6), 93-102.

Chin, K. S., Pun, K. F., \& Lau, H. (2003). Development of a knowledge-based self-assessment system for measuring organisational performance. Expert Systems with Application, 24(4), 443-455.

Hoyle, R. H. (1995). Structural equation modeling: concepts, issues and applications. Thousand Oaks: Sage Publications.

Huang, F. M. (2005). The mode of structural equation: theory and application (in China). Beijing: China Tax Press.

Hussey, D. M. (2007). Using structural equation modeling to test environmental performance in small and medium-sized manufacturers: can SEM help SMEs? Journal of Cleaner Production.

\section{Copyrights}

Copyright for this article is retained by the author(s), with first publication rights granted to the journal.

This is an open-access article distributed under the terms and conditions of the Creative Commons Attribution license (http://creativecommons.org/licenses/by/3.0/). 